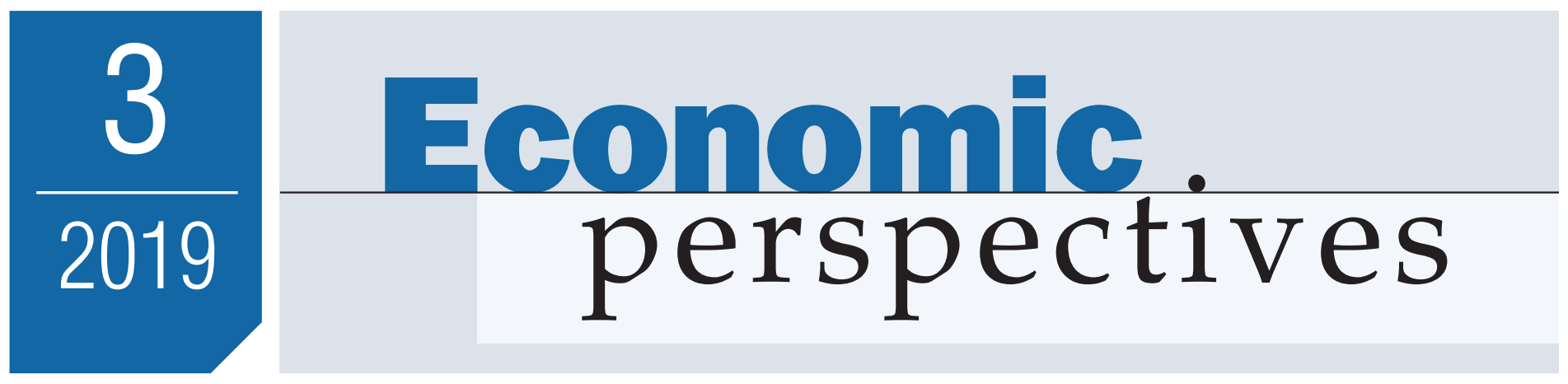

https://doi.org/10.21033/ep-2019-3

\title{
Can broader access to direct CCP clearing reduce the concentration of cleared derivatives?
}

\section{Nahiomy Alvarez}

\section{Introduction and summary}

In November 2008, at the height of the global financial crisis, leaders from the Group of Twenty (G20) nations, representing the world's largest economies, convened in Washington, DC, to develop a new regulatory framework to help foster financial stability. They came out of that Washington summit with several noteworthy ideas. ${ }^{1}$ One was to strengthen over-the-counter (OTC) derivatives markets, where defaults had been serious problems during the financial crisis. In particular, G20 leaders agreed to move more of this business onto regulated exchanges and central counterparties (CCPs) as a way to increase transparency and reduce systemic risk.

CCPs are institutions that guarantee the performance of cleared contracts. After a trade is executed (whether on an exchange, on an alternative electronic trading platform, or through bilateral negotiation) and accepted for clearing, CCPs interpose themselves between each buyer and seller, becoming the new legal counterparty to each original party. CCPs reduce counterparty risk, or the risk that one side will not meet its obligations, in a number of ways throughout the life of a contract. For example, CCPs collect collateral to protect against defaults (see box 1) and have default management frameworks in place to ensure the orderly closeout of portfolios in the event of a default. In this way, CCPs serve as firewalls during times of stress, reducing the risk that the default of one institution leads to a chain reaction.

CCPs have long existed in derivatives markets, but it was not until the global financial crisis that these financial market infrastructures became widely embraced by policymakers. Today, most G20 jurisdictions have implemented some form of a clearing mandate (Barnes, 2017). This has substantially increased the volume of transactions passing through CCPs and resulted in a shift from uncleared bilateral markets to 


\section{BOX 1}

\section{Key terms}

Open interest: Number of derivatives contracts outstanding at any given time

Margin: Amount of financial resources deposited with a central counterparty $(\mathrm{CCP})$ by a clearing member (or between counterparties in noncleared trades) to secure a derivatives contract over time

- Initial margin (IM): Collected by the CCP when clearing members initiate their contracts

- Variation margin (VM): Calculated and collected or distributed by the CCP at least daily to reflect changes in the market value of contracts

Collateral: Financial instrument (for example, cash or securities) used to satisfy a margin requirement cleared markets. In the United States, the clearing mandate under the Dodd-Frank Wall Street Reform and Consumer Protection Act (Dodd-Frank Act) requires that any person or institution trading standardized OTC derivatives must have these transactions cleared at a CCP. As such, CCPs are now of even greater systemic importance to global financial markets. Policymakers and market participants have focused on bolstering individual $\mathrm{CCPs}_{-}-$ by improving risk management frameworks, rules, and practices - and also on identifying vulnerabilities that may pose systemic threats. While considerable progress has been made, some issues remain.

Market participants can access a CCP in two main ways: by becoming a member of the clearinghouse (a clearing member) or by entering into a customer relationship with a clearing member - that is, another institution that can clear trades on their behalf.

When a clearing member clears trades that are entered into for its own account, such trades (as well as the resulting open positions) are known as "house" or "proprietary" trades (positions). When a clearing member clears trades (and carries open positions) for its customers, they are known as "customer" or "client" trades (positions). ${ }^{2}$ Clearing members' customers can include any market participants trading derivatives.

For the past few years, the clearing of derivatives has been chiefly handled by a small number of clearing members at major CCPs across the world. In U.S. derivatives markets, the largest five clearing members (as measured by customer funds) account for over half of all client margin (which is defined in box 1), according to data from the U.S. Commodity Futures Trading Commission (CFTC). Determining whether this concentration is likely to produce worse or better outcomes requires modeling and analysis that are outside the scope of this article. However, various national authorities, international standard setters, and market participants have argued that, unchecked, the consolidation within the clearing industry, which has left derivatives contracts concentrated among a few large CCP clearing members, could be a source of systemic risk. In particular, if a CCP only has a few large members, its ability to effectively manage a member default may be limited for a number of reasons that I discuss later in this article.

One approach some CCPs have adopted to allay such concerns is to encourage major end-users of derivatives that meet CCP membership requirements - for instance, corporations, pension funds, insurance companies, and sovereign wealth funds - to become direct clearing members themselves, rather than remaining customers of other established clearing members (see figure 1). The idea here is that the clearing system could be made more resilient by diversifying the types of clearing members at CCPs; increasing the overall number of clearing members; and redistributing the outstanding cleared derivatives contracts, or "open interest," across a greater number of clearing members (see box 1).

The challenges of adding direct clearing members, however, are significant. For instance, to broaden direct clearing membership, CCPs may need to adjust their settlement processes so that clearing members are permitted to participate in afternoon or ad hoc settlement cycles without substantial amounts of same-day funds on hand. Later on, I examine some of the settlement conventions that are currently being developed at some major CCPs to address the challenges that can inhibit many end-users from becoming direct clearing members at a CCP. 
FICURE 1

\section{What is direct clearing for end-users?}

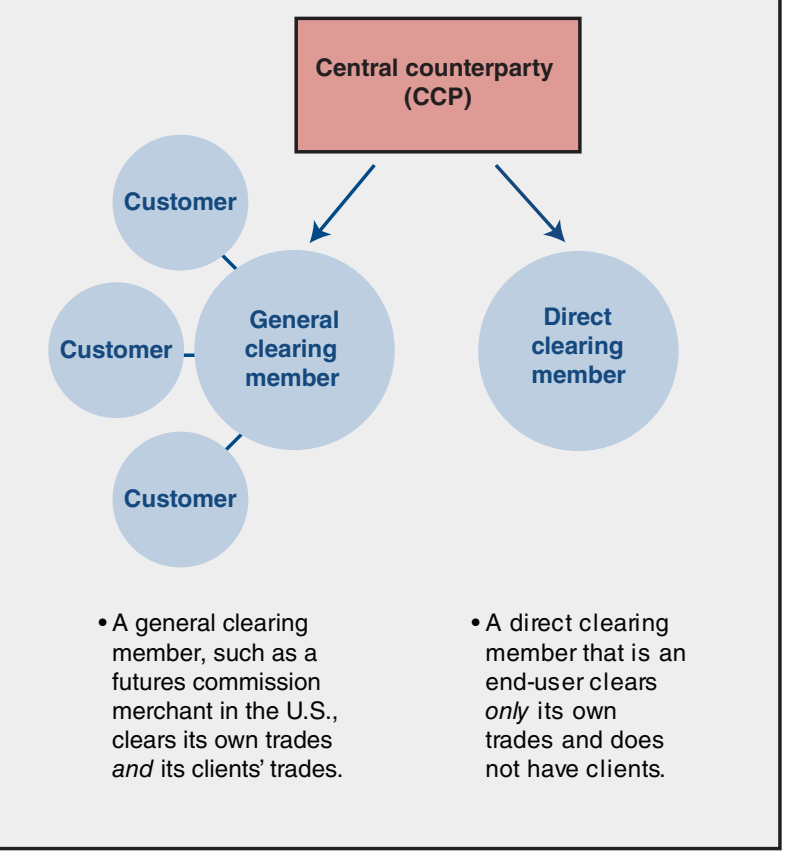

My goal in this article is not to make policy recommendations, but to examine the potential advantages and disadvantages of expanding direct $\mathrm{CCP}$ access to end-users as a means of reducing the concentration of outstanding derivatives contracts among a handful of clearing members at major CCPs. To that end, I discuss the approaches for broadening such access that have been employed or considered at CCPs in Frankfurt, London, and the United States. I also look at other ways for achieving broader access that have been proposed by industry participants and regulators. It is also worth noting that this article does not provide an empirical analysis of industry concentration.

In the following section, I offer some background information on global derivatives markets and central clearing, including the default management process of CCPs. Then, I explore some of the potential drivers and adverse consequences of the existing concentration of outstanding cleared derivatives contracts among clearing members. I discuss options for broadening direct clearing access and the benefits of wider access. Finally, I explain the challenges

for end-users of derivatives looking to become direct clearing members at CCPs - as well as some potential ways to overcome these hurdles.

\section{Background}

In this section, I provide some background information on global derivatives markets and central clearing.

See box 1 for definitions of some key terminology related to cleared derivatives that is used here and throughout the rest of the article.

\section{The role of central clearing in derivatives markets}

When Lehman Brothers defaulted in September 2008, massive market turmoil ensued. One of the reasons for this was that failures of contracts within a complex and opaque web of privately traded, uncleared derivatives — credit default swaps (CDSs) — amplified the crisis (Financial Crisis Inquiry Commission, 2011).

A derivatives contract, as the name implies, derives its value from some underlying asset or group of assets, which can range from interest rates and foreign currencies to commodities, such as oil and sugar. Market participants can trade derivatives bilaterally (that is, over the counter, or off exchange) or on regulated exchanges. Importantly, unlike stocks, which are traded and settled within days, derivatives contracts are often longer-dated commitments (as exemplified by futures contracts). ${ }^{3}$

Derivatives serve an important role in the global economy - they allow market participants to transfer risk. Heckinger (2013) explains how an agricultural chemical company interested in purchasing soybeans in the future at a fixed price faces the risk that the price of soybeans will change unfavorably. To hedge its exposure, or transfer this unwanted risk to another party, the agricultural chemical company can use a derivatives contract to lock in the future price of soybeans. A different market participant, hoping to potentially profit 
from future price changes of soybeans, assumes the price risk that the agricultural chemical company wishes to transfer.

While derivatives are useful risk-shifting tools, the financial crisis exposed how, with little oversight, OTC derivatives transactions had rapidly grown out of control. Characterized for their lack of transparency, OTC derivatives markets were also found to be insufficiently collateralized and risk managed. And yet, as bilateral markets fell into disarray once Lehman was declared insolvent, cleared derivatives markets continued to operate. ${ }^{4} \mathrm{CCPs}$ acted quickly to manage their own risk and then wind down and transfer the multiple positions and numerous client accounts worth trillions of dollars in Lehman's portfolio for which they had assumed responsibility. As Norman (2011) explains, CCPs helped prevent Lehman's default from turning into an even worse outcome for financial markets. Because of this success - and in an effort to address weaknesses in the OTC derivatives markets more broadly - international standard-setting bodies and national authorities set out to move bilateral derivatives trades into a centrally cleared framework.

CCPs offer a wide array of tools that enhance the stability of the financial system as a whole, but they were not designed for this purpose. CCPs were created by market participants as private arrangements to serve their interests in mitigating their own counterparty risk - what John Trundle, of Euroclear SA/NV, called a "collective investment of the market in risk management" (quoted in Evanoff, Russo, and Steigerwald, 2006). Here, by "private," I mean that only the participants of a CCP arrangement are the beneficiaries of its guarantee (although the corporate structure of the CCP itself can vary - a CCP can be set up under a sovereign government, as a nonprofit, as a for-profit corporation, as a hybrid, etc.).

As private arrangements, CCPs are in effect what some have called a "club," where the collective responsibility of clearing members combined with "established membership standards and disciplinary mechanisms" ensures commitment to the rules (Cox and Steigerwald, 2018). For reasons I will discuss, one of the key ways that CCPs manage risk is by limiting membership into their club; CCP membership, like membership at the exchanges out of which they grew, has historically been limited. That raises the question of how society more broadly can benefit from central clearing in the context of post-crisis reforms, such as the clearing mandate. One answer could be to broaden direct participation by end-users of cleared markets for derivatives. However, such broader participation would entail CCPs having to monitor and discipline a larger number of clearing members.

Later on, I discuss the concept and nascent practice of direct CCP clearing by end-users in greater depth. But to better explain the trade-offs between broad direct access to central clearing and narrow access, I first consider how CCPs developed into the institutions they are today.

\section{A brief history of clearing: The development of CCPS}

Moser (1994) and Norman (2011) both discuss the development of central clearing as it is known today in detail. Some of the earliest precursors of CCPs can be traced as far back as the nineteenth century and were described as ring systems. Under these systems, the exchange would determine and conspicuously post end-of-day closing prices for each commodity. Exchange members would then exchange bank checks bilaterally with each member they had traded with. These bank checks reflected the price difference between the price at which their contracts were executed and the posted settlement price for the day. Although participation was voluntary, it was also substantial. Members placed a high value on being part of this arrangementnot to mention the fact that each member had financial exposure to the members it had traded with. As markets matured, this resulted in thousands of bank checks being exchanged. 
Over time, consistent with a desire to be cost-efficient, many exchanges created clearinghouses. The early clearinghouses were not much more than centralized post offices that calculated the net obligations of members by offsetting bank checks that their members would otherwise receive against checks that they would otherwise be obligated to pay. Neither the ring system nor these early clearinghouses eliminated counterparty risk. While the ring system and early clearinghouses added to the efficiency of the market and lowered costs, both had one fatal drawback: The framework was only as strong as its weakest participating member. If any member could not settle its net financial obligation, the advantages of netting broke down completely, with disastrous results.

As centralized clearinghouses matured, members realized that they needed some financial protection against the nonperformance of another member in a transaction. Members agreed to deposit collateral with the clearinghouse to provide some assurance to fellow members trading with them that they could honor their trading obligations. Interestingly enough, the early clearinghouses were simply custodians of this collateral. The clearinghouse itself made no guarantees to the members other than safely holding their collateral. Posting collateral was an added expense to clearinghouse members, yet as more members agreed to do so, the certainty that trades between members would settle properly was increased and, therefore, the value of clearinghouse membership was enhanced.

Throughout much of the nineteenth century, organized markets across the globe made their way through this continuum of credit risk mitigation techniques. Eventually, European markets - and North American markets soon thereafter-introduced "complete clearing" frameworks in the late 1800s. Coined by James Moser (1994), the term "complete clearing" is well established in the literature as a reference to clearing with counterparty substitution. Vuillemey (2019) finds the first known complete clearinghouse for commodities was the Caisse de Liquidation des Affaires en Marchandises, which was formed in 1882 in Le Havre, France. The practice eventually took hold in North America after the first known CCP in the United States, the Minneapolis Chamber of Commerce Clearing Association, was formed in 1891 to support the markets at the Minneapolis Chamber of Commerce (Norman, 2011).

Under a complete clearing framework, a clearinghouse was capitalized by the members, with the capital often serving as a guarantee fund available to cover the financial liability of the clearinghouse. Uniform initial margin levels were determined and collected by the clearinghouse. The clearinghouse also collected the difference in payments made and received by each member - the precursor to today's daily payments of variation margin that account for changes in contracts' value over time (see box 1). Once contract terms were standardized, members no longer cared about the party they had traded with, as performance on the trades was guaranteed at least up to the capital amount of the clearinghouse. This development meant that there was now loss mutualization among the members as their collective contribution to the capital of the clearinghouse was exposed to the nonperformance of any member. In this way, clearinghouse members were sacrificing some autonomy and incurring higher costs, but gaining far greater certainty of contract performance.

This model of clearing became widely adopted (while being incrementally improved) in the twentieth century. The members owned and operated the exchange, and as such, also owned the clearinghouse, either directly or indirectly through the exchange. Membership criteria were quite important as the members knew all too well that the failure of any member to perform would reflect adversely upon the exchange, themselves, and their clearinghouse as a whole. This "all for one and one for all" approach prevailed throughout most of the twentieth century.

Late in the twentieth century and early in the twenty-first century, exchanges and their clearinghouses incorporated as publicly traded corporations (with a profit motive). This represented a significant departure from the member-owned and member-controlled model. Nonetheless, each of these complete clearinghouses continued to be supported by a mutualized guarantee fund contributed by their members. 
In sum, CCPs evolved in a way that ensured they had direct contractual relationships only with parties that were clearing members. ${ }^{5}$ Today, market participants looking to clear their trades must be either a clearing member or the customer of one that can clear on their behalf. In the United States, a clearing member that clears trades for customers in derivatives markets is called a futures commission merchant, or FCM. ${ }^{6}$

\section{How do CCPs manage risk?}

CCPs have rulebooks with processes laid out to ensure that their clearing members can meet their obligations. Besides the setting of membership criteria — what CCPs often call "the first line of defense" - CCPs require clearing members to post initial margin throughout the life of a derivatives contract, and can decide what types of collateral to accept to satisfy that initial margin obligation. CCPs also mark to market, or revalue, the trades on their books, at least daily, so that CCPs pay out variation margin to clearing members that have net gains on their positions and collect VM from clearing members with net losses. In turn, clearing members have the responsibility of collecting margin from and paying margin to their customers.

Moreover, as the counterparty in a large number of transactions, a CCP can provide multilateral netting. This entails summing up and offsetting the amounts a CCP owes each of its clearing members with the amounts each member owes that CCP during a settlement cycle (before single net amounts are paid to either the CCP or its members). By reducing the overall number of counterparty relationships that members would otherwise have, a CCP delivers, through multilateral netting, lower overall risk exposures and trade settlement costs, among other benefits, to its members (Norman, 2011). Because a CCP is not investing in the market for its own account, a CCP runs a matched book, where any position taken by one counterparty is offset by an equal and opposite position taken by another counterparty (McPartland, 2005). In other words, the total number of the long positions must equal the total number of the short positions at all times.

A CCP seeks to operate with a matched book that relieves it of any exposure to a change in the market value of the positions that it guarantees. However, a clearing member default would leave the CCP with an unmatched book. To mitigate the risk from a potential clearing member default, CCPs require that all clearing members contribute to a mutualized guarantee fund that is used to cover losses from a clearing member default that exceeds the defaulter's own financial resources at the CCP.

The mutualization of losses is a crucial element of CCP risk mitigation. When a clearing member defaults, a CCP will first draw on the IM and guarantee fund contribution of the defaulting clearing member. The IM and guarantee fund contribution form the top of a CCP's "default waterfall," which stipulates the order of financial resources that a CCP can draw upon to cover the unmet financial obligations of the clearing member in default. A CCP will only draw on the remainder of the default waterfall, which includes contributions to the guarantee fund from other clearing members and in some cases the CCP itself, if losses exceed the defaulter's resources in the waterfall. Importantly, because of the mutualization of risk across clearing members, clearing members have an incentive to aid in the default management process of a CCP.

In order to minimize losses following the default of a clearing member, CCPs have to do at least three things in a timely manner (Lewis and McPartland, 2018). First, CCPs must continue to meet financial obligations to nondefaulting clearing members. Second, they must return to a matched book by either liquidating the house positions of the defaulter or auctioning them to other clearing members. Third, they must attempt to transfer the client positions of the defaulting clearing member. Achieving the second and third outcomes may depend critically on the number of clearing members the CCP has; the larger the share of open interest a defaulting member has, the larger the (relative) default losses there are and the more difficult it is for the $\mathrm{CCP}$ and the surviving members to deal with them. As the International Swaps and Derivatives Association (2019) has noted, 
mutualization of risk in a CCP works best if that risk is mutualized across many members. If the membership of a CCP is too concentrated, liquidation via an auction is less likely to yield a good price. This is the case particularly if other clearing members have positions in the same direction as the defaulter.

Of course, clearing does come with costs. For market participants that rely on CCP clearing members as financial intermediaries, these may include having to post margin and pay the clearing member for its services. Costs associated with clearing for market participants that become direct clearing members of CCPs include having to post margin and meet the membership requirements of various CCPs. Generally, CCP membership requirements include the ability to maintain a minimum level of capital, a risk management capability, and operational preparedness. But certainly many market participants, even those that are not subject to the clearing mandate, find the benefits of centrally clearing their trades well worth the costs. As a recent paper from an end-user perspective notes,

the reduction in bilateral counterparty credit risk, increased market transparency, together with the improved efficiency in trade execution outweigh the significant operational costs incurred by market participants and end-investors to comply with clearing mandates. In fact, a number of market participants who are not subject to clearing mandates, including end-investors, do decide to clear voluntarily. This indicates that clearing mandates may not always be necessary and that these firms see advantages in clearing. (Novick et al., 2018)

In the remainder of this article, I discuss why the rising concentration of cleared derivatives among current $\mathrm{CCP}$ clearing members motivates me and others to look for ways to increase the number of members while retaining the benefits of central clearing. I then delve into the difficulty and promise of direct clearing for end-users as an approach to addressing this challenge.

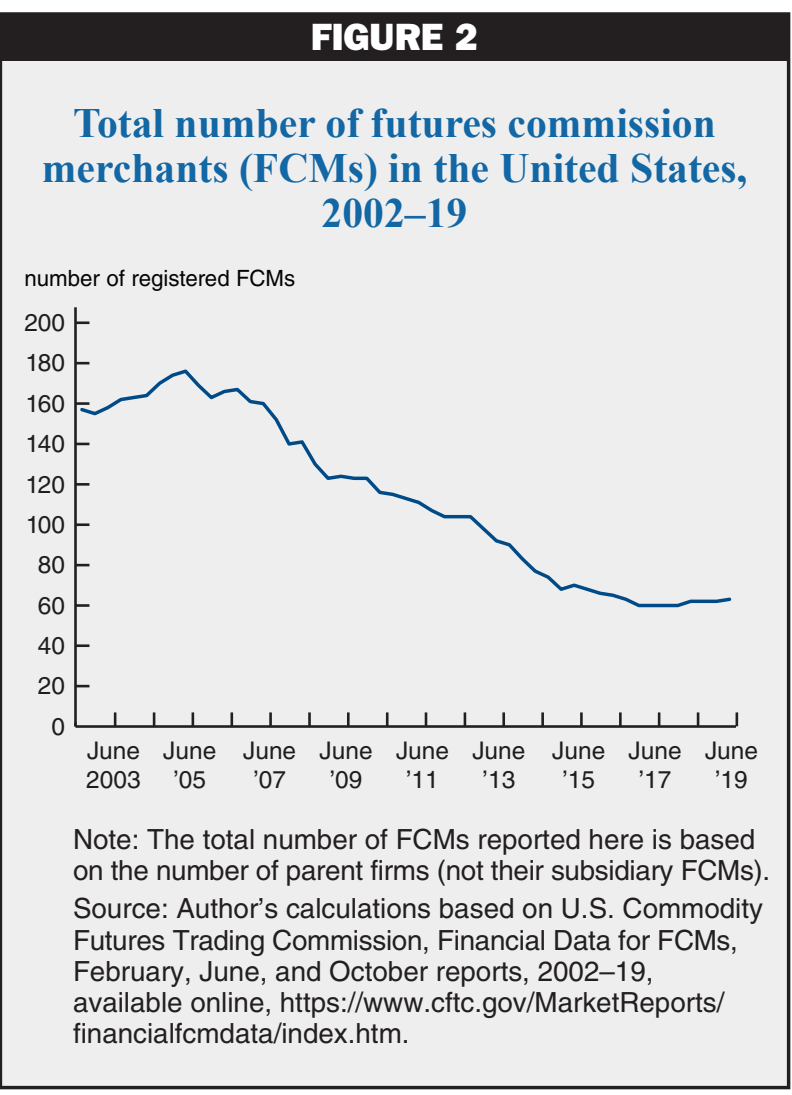

\section{The concentration in derivatives clearing markets}

Since the early 2000 s, there has been a growth of concentration in client clearing markets across the globe. ${ }^{7}$ Over the past two decades or so, a steady number of clearing members have exited the industry while few new players have entered the space. This trend is seen, for instance, in the United States: Figure 2 shows that the number of FCMs registered with the CFTC has more than halved since 2002.

As of June 2019, there were 63 FCMs registered with the CFTC, down from a peak of 176 FCMs in the mid-2000s. For swaps specifically, the client clearing landscape is even more consolidatedfewer than 20 FCMs handle all swaps clearing.

At the same time, a small number of large, predominantly bank-affiliated clearing members account for the vast majority of house and customer positions and most of the financial resources provided by clearing members to CCPs. Figure 3 shows total customer funds held by individual FCMs. ${ }^{8}$ 


\section{Concentration of customer funds among futures commission merchants (FCMs) in the United States, 2019}

\section{Top 20 FCMs}

Citigroup

J.P. Morgan

Morgan Stanley

Goldman Sachs

Merrill Lynch

Société Générale

Credit Suisse

Barclays

Wells Fargo

UBS

ADM Investor Services

Interactive Brokers

Mizuho

BNP Paribas

R.J. O'Brien \& Associates

HSBC

Deutsche Bank

RBC Capital Markets

ABN AMRO

INTL FCStone
Total customer funds

$\$ 38,380,485,609$

$\$ 37,747,558,068$

$\$ 37,008,793,491$

$\$ 36,382,693,683$

$\$ 28,272,032,206$

$\$ 19,522,903,615$

$\$ 18,857,251,342$

$\$ 13,864,053,231$

$\$ 11,829,939,098$

$\$ 7,454,807,828$

$\$ 4,248,330,534$

$\$ 4,202,467,751$

$\$ 4,003,856,788$

$\$ 3,977,290,427$

$\$ 3,644,962,811$

$\$ 3,041,337,586$

$\$ 2,820,794,278$

$\$ 2,710,159,085$

$\$ 2,561,742,458$

$\$ 2,139,344,434$

\section{Five largest FCMs, by customer funds}

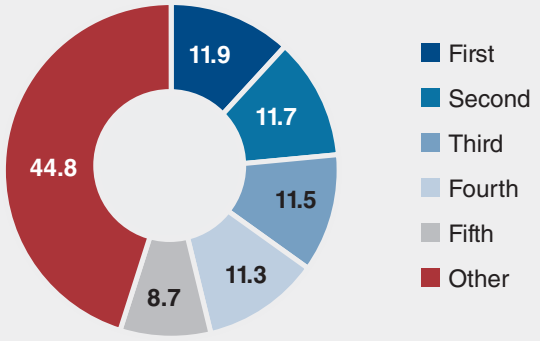

Ten largest FCMs, by customer funds

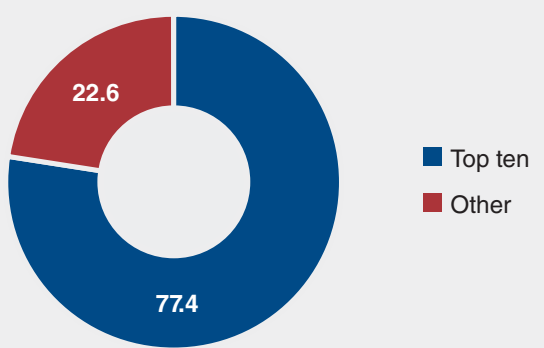

Notes: See note 8 for details on the makeup of customer funds. All pie chart values are in percent and may not total because of rounding. The ranking of the FCMs is based on a measure of total customer funds at the parent firm level (not the subsidiary FCM level).

Source: Author's calculations based on U.S. Commodity Futures Trading Commission, Financial Data for FCMs, February 28, 2019, report, available online, https://www.cftc.gov/MarketReports/financialfcmdata/index.htm.

In U.S. derivatives markets today, the largest five FCMs (as measured by customer funds held) account for almost 60 percent of all customer funds - up from about 45 percent in 2002 - and the top ten FCMs account for a little over 80 percent—up from around 70 percent in 2002 (see figure 4).

This trend is also seen globally. According to a comprehensive 2017 study of 26 CCPs across 15 jurisdictions in North and South America, Europe, and Asia, the largest 20 clearing members - as measured by contributions to CCPs' prefunded financial resources (that is, initial margin plus guarantee fund contributions) accounted for roughly 75 percent of all such contributions from a total of 307 clearing members (Basel Committee on Banking Supervision et al., 2017, p. 2). With regard to client clearing for OTC derivatives specifically, its provision is generally concentrated: For instance, five clearing members (all bank-affiliated) account for more than 80 percent of total client margin for cleared interest rate swaps in the United States, the United Kingdom, and Japan (Basel Committee on Banking Supervision et al., 2018a, p. 3).

Many factors are playing a role in these trends. Some market observers, such as former CFTC Chairman Timothy Massad, have argued that changes in business models, a low-interest rate environment, and changing customer preferences may be key factors (U.S. Commodity Futures Trading Commission, Market Risk Advisory Committee, 2015, p. 173). Others point out that the benefits of clearing are amplified by economies of scale, which may be difficult for FCMs with fewer resources to achieve (Siedlecki, 2017; and Lazarow, 2011). For instance, a bank-affiliated FCM may be better capitalized and have robust collateral management systems that allow it to optimize how its capital is deployed. In turn, this may provide clients with intraday liquidity, lower costs, and margin efficiencies, among other benefits. 


\section{FIGURE 4}

Share of total customer funds held by the largest futures commission merchants (FCMs) in the United States, 2002-19

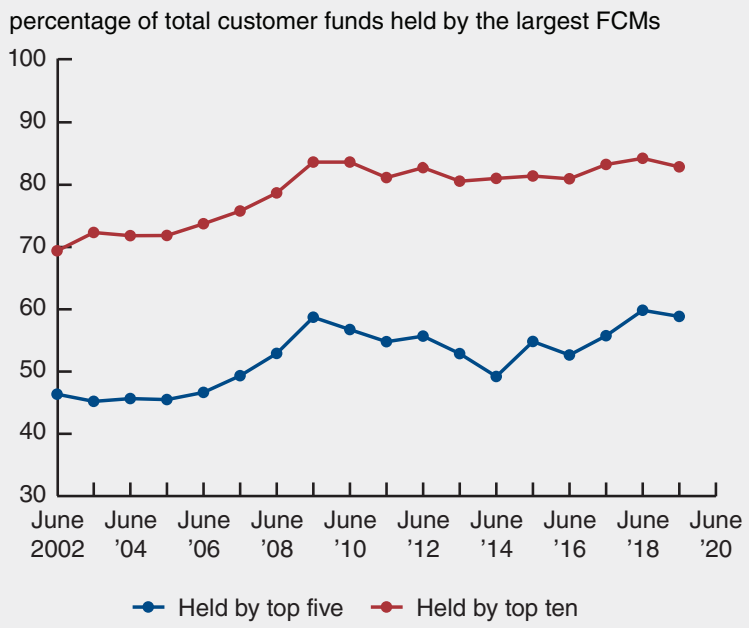

Notes: See note 8 for details on the makeup of customer funds. The ranking of the FCMs (top five or top ten) is based on a measure of total customer funds at the parent firm level (not the subsidiary FCM level).

Source: Author's calculations based on U.S. Commodity Futures Trading Commission, Financial Data for FCMs, June reports, 2002-19, available online, https://www.cftc.gov/MarketReports/financialfcmdata/ index.htm.
Still others, such as CFTC Commissioner Brian Quintenz (2018), point to specific regulatory changes - in particular, the Basel III leverage ratio or its U.S. implementation, the supplementary leverage ratio (SLR) - as possible contributors to the decline in the number of FCMs.

The Basel III framework includes new capital surcharges for global systemically important banks (G-SIBs) and a 3 percent leverage ratio (or 5 percent SLR for large U.S. banks) - which establish the amount of capital a bank must hold relative to its total assets and hence a bank's loss-absorbing buffer to cover defaults on those assets. These and other new regulations have successfully contributed to bringing about a better capitalized banking system than existed before the crisis.

However, the standards used today may overstate the potential loss exposure of a bank's derivatives portfolio relative to other assets, as others have explained. ${ }^{9}$ Because of this, some argue that the SLR may be generating excessive costs of carrying a large derivatives book and hence may have had the unintended consequence of disincentivizing some firms' clearing activity. ${ }^{10}$

Industry news outlets report that after the implementation of the Basel III leverage ratio requirement in various jurisdictions, some clearing brokers withdrew from the client clearing business as it became less profitable (Parsons, 2017; and Vaghela, 2015). In more formal analysis, Acosta-Smith, Ferrara, and Rodriguez-Tous (2018) find that in the United Kingdom both the daily volume of transactions and the total number of customers for clearing members fell after the new requirement went into effect. In the United States, a CFTC policy brief by Haynes, McPhail, and Zhu (2018) shows that after January 2015when large banks had to start disclosing their leverage ratios on a quarterly basis as part of the regulatory phase-in process - the market share of clearing intermediation shifted from firms subject to higher leverage requirements to firms subject to lower ones.

Regulators have taken note of these developments. CFTC Commissioner Brian Quintenz (2018) noted that "unless the treatment of client margin changes, I fear we will see FCMs continue to exit the clearing business and the worrisome trend of FCM consolidation will continue." Similarly, Federal Reserve Board Chair Jerome Powell (2017) said:

Global authorities also have a responsibility to ensure that bank capital standards and other policies do not unnecessarily discourage central clearing. In my view, the calibration of the enhanced supplementary leverage ratio (SLR) for the U.S. global systemically important banks (G-SIBs) should be reconsidered from this perspective. 
Recently, standard-setting bodies, including the Financial Stability Board and the Basel Committee on Banking Supervision (BCBS), have revisited the issue and made some changes. ${ }^{11}$ Notably, in 2019, the BCBS agreed on a targeted and limited revision of the leverage ratio to allow initial margin received from clients to offset the exposure amounts of derivatives centrally cleared on their behalf by bank-affiliated clearing members (Basel Committee on Banking Supervision, 2019).

While it is useful to bear in mind how post-crisis reforms may have impacted clearing, it is difficult to point to a single driver of the concentration and consolidation in the clearing industry. After all, bank-affiliated FCMs remain the largest clearing members despite bearing higher regulatory capital costs; this suggests economies of scale and possibly other factors importantly contribute to concentration in the space.

\section{Consequences of concentration}

The prevalent view among policymakers and regulators is that the concentration of financial exposures in a handful of large clearing members (partly due to industry consolidation) can have a number of adverse consequences, some of which may have systemic risk implications. Next, I highlight some of the key concerns about the current state of the clearing industry.

\section{Default management challenges}

One frequently cited concern about the state of the clearing industry today is that managing the default of a clearing member may be more difficult for a $\mathrm{CCP}$ in an environment where outstanding cleared derivatives contracts are already concentrated among the surviving clearing members.

As mentioned earlier, once a clearing member defaults, a CCP must do at least three things in a timely manner to minimize losses: It must continue to meet its financial obligations to nondefaulting clearing members, return to a matched book, and transfer the client positions of the defaulting clearing member. These are important aspects of the default management process, given that a CCP does not eliminate risk but rather transforms it and then mutualizes it among the remaining clearing members.

To that end, following a default, a CCP may call upon nondefaulting clearing members to absorb the client positions of the defaulter. The challenge is that surviving clearing members may be unable or unwilling to accept new customers and their positions.

Having a nondefaulting clearing member absorb the defaulter's positions will either add to or partially liquidate the existing positions of that surviving clearing member. If the FCM is a subsidiary of a bank, taking on more positions may require not only additional IM, but additional regulatory capital. If a clearing member wanted to avoid this scenario, it could opt to not bid on a defaulter's positions at all or it could submit a "bid to miss," hoping that another clearing member would win the auction. However, at many CCPs, employing this strategy would cause the low-bidding clearing member's contribution to the mutualized guarantee fund to be "juniorized." 12

Officials from the Federal Reserve, CFTC, and the U.S. Securities and Exchange Commission (SEC) have spoken about the challenge of default management amid the rising concentration of cleared derivatives contracts among a small number of FCMs (Behnam, 2018; Peirce, 2017; and U.S. Commodity Futures Trading Commission, Market Risk Advisory Committee, 2015, pp. 147-150). For instance, at an industry event, former CFTC Chairman J. Christopher Giancarlo (2017) stated: "A consolidated FCM industry could pose difficulties in transferring customer positions and margin to other FCMs in times of stress or an FCM default. In certain exchange-traded derivatives markets, three to four firms clear nearly half of the 
trades cleared. Such concentration can potentially impact market functioning and be a source of systemic risk." Similarly, CFTC Commissioner Rostin Behnam (2018) has noted that mass liquidations of client positions stemming from a CCP's inability to transfer client positions to surviving clearing members could exacerbate market volatility and perpetuate the cycle of stress.

\section{Impact on loss mutualization}

Another concern about the current state of the clearing industry is the potential impact on loss mutualization from one of the large clearing members defaulting on its obligations. The resulting default loss could easily entail having to use the mutualized portion of the guarantee fund. Thus, the surviving clearing members would each have to bear a large and immediate financial loss exactly when some of them could have to set aside additional regulatory capital (if they won all or part of the auction for the proprietary positions of the defaulter or if they take on former clients of the defaulter). Fewer clearing members can only mean that there are fewer of them to absorb any mutualized losses.

\section{Interdependencies of CCPS}

In today's clearing environment, not only is client clearing concentrated among a handful of CCP clearing members, but those clearing members are also highly interconnected. A 2018 study on central clearing interdependencies finds that the largest 11 clearing members globally (as measured by contributions to CCPs' prefunded financial resources) operate in between 16 and 25 CCPs (Basel Committee on Banking Supervision et al., 2018b, p. 4). So, should one of the largest 11 clearing members default in one CCP, it could result in the concurrent default of the same entity or its affiliates at up to 24 other CCPs. Moreover, some of the largest clearing members or firms under the same holding company also provide other financial services to CCPs in different capacities - serving as settlement banks, custodians, and providers of lines of credit. According to data from that 2018 global study, 27 percent of clearing members provide credit and liquidity facilities to at least one CCP, 26 percent are investment counterparties to a CCP, and 16 percent provide intraday liquidity to a CCP (Basel Committee on Banking Supervision et al., 2018b, pp. 4, 8). Given that many of the same banks provide such services to CCPs in multiple financial centers,

11 this is yet another way that the default of one large, interconnected, bank-affiliated clearing member could possibly affect multiple CCPs.

\section{Reduced access to clearing services}

As CFTC Commissioner Dan Berkovitz (2019) has noted, the concentration of client clearing services not only presents systemic risks, but also provides fewer choices for end-users of derivatives. In recent years, a number of end-users have expressed concerns regarding the effect of such industry concentration on their access to clearing. Many clearing members have taken actions that have adversely affected end-users' access to clearing; for instance, clearing members have raised client fees or offloaded unprofitable customers, and some clearing members have even exited the derivatives clearing business altogether (Madigan, 2015). As a result, some end-users - including smaller customers that trade relatively infrequently and are less profitable to clearing members - have reported facing hurdles in securing or maintaining their clearing arrangements (Rundle, 2017; and Basel Committee on Banking Supervision et al., 2018a). And many of these end-users are subject to the clearing mandate.

For these reasons, market observers and various industry participants have discussed - and in some cases implemented - alternatives that enable end-users to clear derivatives contracts outside of the standard customer relationships with clearing members by becoming direct legal counterparties to a CCP. 


\section{Direct clearing by end-users as a potential solution to increasing concentration}

End-users today can access clearing almost exclusively through a clearing member. However, as illustrated in figure 1, direct clearing for end-users enables end-users that meet CCP membership requirements (typically, major end-users of derivatives, such as corporations or pension funds) to become direct legal counterparties to CCPs instead of having to rely on established clearing members (referred to as "general clearing members" in figure 1). In my conception, the new direct clearing members seeking to self-clear their proprietary positions with a CCP do not have clearing clients of their own, and they rely on either sponsored or nonsponsored access to that CCP.

\section{Sponsored access}

In sponsored clearing arrangements, end-users become the counterparties to a CCP but still rely upon a sponsoring clearing member for operational services and/or a financial guarantee, depending on the model. Importantly, the end-user's positions and IM are held in a single segregated account at the CCP (separate from its sponsoring clearing member's positions and IM). In this way, an end-user's IM assets are protected in the event its sponsoring clearing member defaults.

For U.S. end-users in particular, this type of arrangement may also protect them from "fellow customer risk" - that is, the risk posed by one or more of the FCM's other customers defaulting on their obligations (FIA, 2012). An FCM cannot use the funds of one customer to meet the obligations of another; nevertheless, an FCM's customers are exposed to the risk from another customer being unable to meet its obligations, given that the associated losses may be too large to bear by the FCM, in which case the FCM itself may face default.

Some CCPs currently offer or have previously proposed sponsored access to direct clearing. In the following bulleted paragraphs, I describe four models of sponsored access.

- ICE Clear Europe's Individual Segregation through Sponsored Principal Account offers a market participant (the sponsored principal) and a sponsoring clearing member a joint account with the CCP. Under this model, the sponsor and sponsored principal are jointly liable for all positions in this account. Sponsoring clearing members are also responsible for the sponsored principal's guarantee fund contribution. Should the sponsoring clearing member default, however, the CCP will continue to settle margin with the sponsored principal. This model is available with all of ICE Clear Europe's clearing services (for example, for futures and options, OTC credit default swaps, and OTC foreign exchange), but to date, clients of U.S. FCMs cannot become sponsored principals (for details, see ICE Clear Europe, 2019).

- Eurex Clearing's ISA Direct model has offered eligible insurance companies, reinsurance companies, financial institutions, pension funds, and investment funds domiciled in the European Union (EU) or Switzerland (ISA Direct members) direct clearing membership with the CCP. In this model, the ISA Direct member is responsible for providing IM and VM, as well as its guarantee fund contribution; additionally, the ISA Direct member must bid in an auction of a defaulter's portfolio. A clearing agent may provide some of the requisite services for the ISA Direct clearing member to clear with the CCP, but the financial obligation remains that of the ISA Direct member. In other words, the clearing agent does not guarantee performance of the ISA Direct member; if the clearing agent does not fulfill the requisite service, the $\mathrm{CCP}$ would declare the ISA Direct member to be in default. In this regard, the Eurex Clearing model deviates from the other sponsored models I discuss. Under this arrangement, the 
clearing agent (if a bank or bank subsidiary) does not face any regulatory capital and balance sheet implications from working with the ISA Direct member. This mode ${ }^{13}$ is limited for use in trading OTC interest rate swaps and cleared repurchase agreements (repos). ${ }^{14}$

- CME Clearing's previously proposed Direct Funding Participant (DFP) model offered market participants individual membership with the CCP, allowing them to post margin directly at the CCP. However, unlike Eurex Clearing's ISA Direct model where the clearing agent does not guarantee performance of the participant, the DFP model required a DFP guarantor to be responsible for the DFP's guarantee fund contributions and performance. In other words, a DFP would settle its margin requirement directly with the CCP, but if it did not, its financial obligations would need to be met by its DFP guarantor. This model was limited to asset classes for which guarantors were clearing members. ${ }^{15}$

- Though the focus of this article is on CCPs that clear derivatives contracts, it's worth noting that CCPs that clear securities are also considering models to widen direct clearing membership. Fixed Income Clearing Corporation's (FICC) Sponsored Membership model, approved by the SEC in March 2019, offers market participants (that is, sponsored members) the ability to provide collateral and liquidity to the repurchase agreement market (this has traditionally been done by banks and broker-dealers). As in other models, a sponsoring member is required. While a sponsored member is liable to the FICC for its securities and settlement obligations, the sponsoring member must provide a guarantee to the FICC in the event its sponsored member fails to satisfy its obligations. This arrangement also allows for some balance sheet and regulatory capital relief opportunities to the clearing member that is the sponsoring member (relative to the traditional clearing member-client relationship) ${ }^{16}$

\section{Nonsponsored access}

Another alternative to relying on a clearing member to clear trades is for end-users that meet CCP membership requirements to become direct clearing members without a sponsor and self-clear their trades. This could take two forms. Large end-users could choose to become independent direct clearing members of one or more CCPs. Or a small group of market participants from the same industry could form a cooperative that becomes a clearing member at one or more CCPs to clear their own trades.

\section{Benefits of direct clearing by end-users}

Direct clearing by major end-users would redistribute open interest across a greater number of clearing members. Doing so could counteract the growing concentration in derivatives clearing and some of its adverse consequences. Moreover, CCPs might find it easier to manage a clearing member default in an environment that is less concentrated. More direct clearing members would expand the universe of potential bidders on the derivatives portfolio of a defaulting clearing member. In turn, this might improve auction results and help minimize potential losses incurred by the CCP. End-users that had become direct clearing members would also not face the risk of a CCP being unable to port their positions to another clearing member in the event of a clearing member default, and their positions and IM assets would already be held in their own accounts at the CCP. ${ }^{17}$

If more major end-users were to become direct clearing members of CCPs and outsource their post-trade processing to bank-affiliated clearing members, one might also expect such an increase in membership to reduce the overall costs currently associated with client clearing by bank-affiliated clearing members. For one, the IM assets of a bank-affiliated clearing member's customers that became direct clearing members would no longer be reflected on the balance sheet of the bank-affiliated clearing member and would therefore no longer be consolidated onto the parent bank's balance sheet. Moreover, the notional principal of the 
direct clearing member's positions would no longer be included in the parent bank's SLR calculation. This would lessen the leverage of the bank and thus lower the required regulatory capital of bank-affiliated clearing members. ${ }^{18}$

From a public policy perspective, it is worth noting that this structure provides the same risk-absorption capacity from IM without the regulatory costs associated with booking the IM and the positions at a bank. In this way, the structure does not increase overall risk in the clearing system.

Lastly, in the United States, some FCMs should see reduced overnight and intraday liquidity requirements. Under U.S. law, FCMs that carry customer accounts are required to maintain customer funds segregation. Among other things, this means that such FCMs must maintain an appropriate residual interest ${ }^{19}$ (FCM funds deposited in the customer account, in addition to the customer funds) to avoid using the funds of one customer to secure positions held for a different customer. Currently, many of the larger FCMs have large overnight liquidity requirements to accommodate the customary one-day lag of customers settling with their FCM. This liquidity buffer only applies to FCMs that carry customer accounts because of the requirement to keep customer funds in segregation. With fewer large customers, these FCMs could hold a smaller liquidity cushion. And for their part, the large end-users (former large customers of FCMs) that have become direct clearing members are not required to maintain residual interest.

Despite these benefits, becoming direct clearing members is not without significant challenges for many end-users, which I cover next.

\section{The challenges of direct clearing membership facing potential end-user candidates}

Any single end-user considering whether to become a direct clearing member will face a number of challenges. These challenges can be divided into two main categories: 1) their viability as a potential candidate and 2) the practical obstacles and financial considerations of becoming a direct clearing member.

\section{Who can potentially become a direct clearing member?}

The concept of the end-user as direct clearing member only works for enterprises where all derivatives contracts are entered into for the account and risk of the enterprise itself. Large end-users such as corporations, pension funds, insurance companies, and sovereign wealth funds are viable candidates for becoming direct clearing members. Becoming a direct clearing member would not be possible for an investment manager because it is legally acting as an agent for multiple beneficial owners of the managed portfolio; under the law, the positions that the investment manager initiates are for the account and risk of the beneficial owners of the managed portfolio. ${ }^{20}$ In the theoretical case of an investment manager as clearing member, the positions would not be the proprietary positions of the clearing member.

So, a large individual end-user could become a direct clearing member, but how about a small one, that is, one with more limited resources? Another approach to direct CCP membership is for several end-users to form a cooperative that becomes a clearing member. Imagine seven coffee merchants in London that are experiencing difficulty obtaining and maintaining reasonable clearing relationships with $\mathrm{CCP}$ clearing members. If the coffee merchants jointly capitalize an entity that becomes a clearing member and it only executes and clears their proprietary coffee trades, that clearing member would not be considered an intermediary doing customer business in most regulatory jurisdictions. Depending on the applicable law, the same would be true if seven family members formed their own enterprise that became a direct clearing 
member and it only executed proprietary trades for those seven family members. This approach enlarges the potential pool of new direct clearing members.

While this potential pool may be big, there are still some factors that limit it. For one, many small end-users lack the resources for direct clearing membership to make financial sense (European Securities and Markets Authority, 2016), and they may not want to form a cooperative to directly clear their derivatives contracts with a CCP for strategic reasons. Unless they place a particularly high value on eliminating fellow customer risk and the risk from their clearing member defaulting, they wouldn't necessarily seek direct clearing membership themselves. For another, because CCPs mutualize losses among their clearing members, there could be a question of whether the existing clearing members would be willing to participate in loss mutualization with a new group of direct clearing members. In practice, only CCPs have the ability to set membership criteria. However, like their members, CCPs consider membership criteria a key aspect of their risk management framework and therefore set operational and financial requirements that not every end-user may be able to meet.

\section{How can end-users become direct clearing members?}

Even when end-users are viable candidates for direct clearing membership, they may face other challenges in becoming CCP clearing members. In the remainder of this section, I further examine these hurdles - as well as some approaches that could be taken to overcome them.

Clearly, one hurdle that potential direct clearing members face is the additional head count and expense required to handle all the post-trade processing that membership entails.

Another hurdle for potential direct clearing members is the requirement to contribute to the CCP's mutualized guarantee fund. Moreover, potential members may also be required to pay additional member assessments to the CCP if all the prefunded financial resources are depleted as a result of a member default. Some potential members may not wish to take on these obligations.

15 The third hurdle is the most formidable one. CCP clearing members typically need to hold substantial amounts of cash in reserve in order to meet a potential VM obligation as part of an afternoon or ad hoc settlement cycle. However, many potential direct clearing members have their cash fully invested in the morning, so they will not have the necessary same-day funds on hand.

I examine how CCPs could adjust their settlement processes so that direct clearing members could participate in afternoon or ad hoc settlement cycles without substantial amounts of same-day cash. As an increasing number of CCPs pay market rates of interest on IM cash deposited by clearing members, there may be an opportunity to repurpose that cash to cover the same-day funds requirement for end-users that have become direct clearing members and to make the clearing ecosystem more resilient. ${ }^{21}$

Next, I discuss each of these three challenges in greater detail and consider ways that they may be addressed.

\section{Challenge 1: The additional head count and expense for post-trade processing}

One of the first challenges a potential direct clearing member (particularly one without sponsored access) faces is the additional head count and expense needed for post-trade processing as a clearing member. A potential direct clearing member may find that it is not cost-effective to establish a back-office operation to carry out the additional administrative work. However, the costs associated with post-trade processing need not be a deterrent to direct clearing membership. Potential direct clearing members could, for instance, opt to 
outsource their post-trade processing to a third-party service provider or another clearing member under what is called a "facilities management agreement."

Facilities management agreements are not a new concept. In fact, they were fairly common in the early 1980s. Agreements of this sort can offer benefits to all parties involved. End-users that have become direct clearing members will benefit from outsourcing their operational responsibilities to another clearing member, most likely their current FCM (in a U.S. context). Clearing members providing facilities management services to the new direct clearing members would be replacing a somewhat unpredictable, transactions-driven revenue stream with a relatively more stable one. Facilities management agreements also give the CCP appropriate assurances that the clearing member providing facilities management services is assuming all of the outsourcing clearing member's operational (but not financial) responsibilities that are important to the CCP. As such, facilities management agreements may not require additional regulatory scrutiny.

That said, this framework is highly contingent upon end-users being satisfied with paying the same amount for facilities management services when they become direct clearing members as they did for clearing and credit intermediation when they were customers of clearing members.

In recent years, at least one large bank FCM outsourced its futures and other derivatives clearing operations, including post-trade processing, to a third party (Parsons, 2018). Assuming some of today's customers of clearing members eventually become direct clearing members themselves, some bank-affiliated FCMs that handle post-trade processing for these new clearing members under facilities management agreements could see their return on equity (ROE) increase on a revenue-neutral basis. This would happen because the FCMs would be maintaining approximately the same revenue stream (from fellow clearing members who used to be their customers), but without many of the factors currently affecting the required regulatory capital of their parent banks. Similar revenue generated on a lower capital base increases ROE. Even at levels below revenue neutral, the concept of the end-user as direct clearing member could still be financially attractive to bank-affiliated clearing members if relief from capital requirements were sufficient to make up for any shortfall.

\section{Challenge 2: The obligation to mutualize potential losses}

Another complicating factor for some potential direct clearing members ${ }^{22}$ is the requirement to contribute to the CCP's mutualized guarantee fund. Potential direct clearing members might be able to avail themselves of alternative solutions to satisfy their guarantee fund obligations.

For example, a pension fund that has become a direct clearing member might purchase a bank certificate of deposit (CD) from the parent bank of the clearing member (an FCM) that's providing it with facilities management services. This CD would be equal to the pension fund's guarantee fund obligation as a new direct clearing member. The parent bank of the established clearing member would then use the proceeds of the CD to pay for the guarantee fund obligation of the new direct clearing member (that is, the pension fund) and assume all of the risks for doing so. ${ }^{23}$ The parent bank of the FCM would need to be compensated for assuming the contingent risks inherent in all guarantee fund contributions, as well as the capital charges that come with the associated increase in its balance sheet. The pension fund would own a negotiable bank $\mathrm{CD}$ and would only have the same depositor risk inherent in any term bank deposit. ${ }^{24}$ Figure 5 illustrates this process.

Should some demand for this alternative type of service develop, it is conceivable that sureties would compete to provide guarantee fund contributions that were not directly funded by a direct clearing member. The risk of loss would be the same, but there would be an additional charge for funding the default guarantee fund contribution for some mutually agreed-upon term. 


\section{Alternative process for end-user that has become a direct clearing member to meet its guarantee fund obligation}

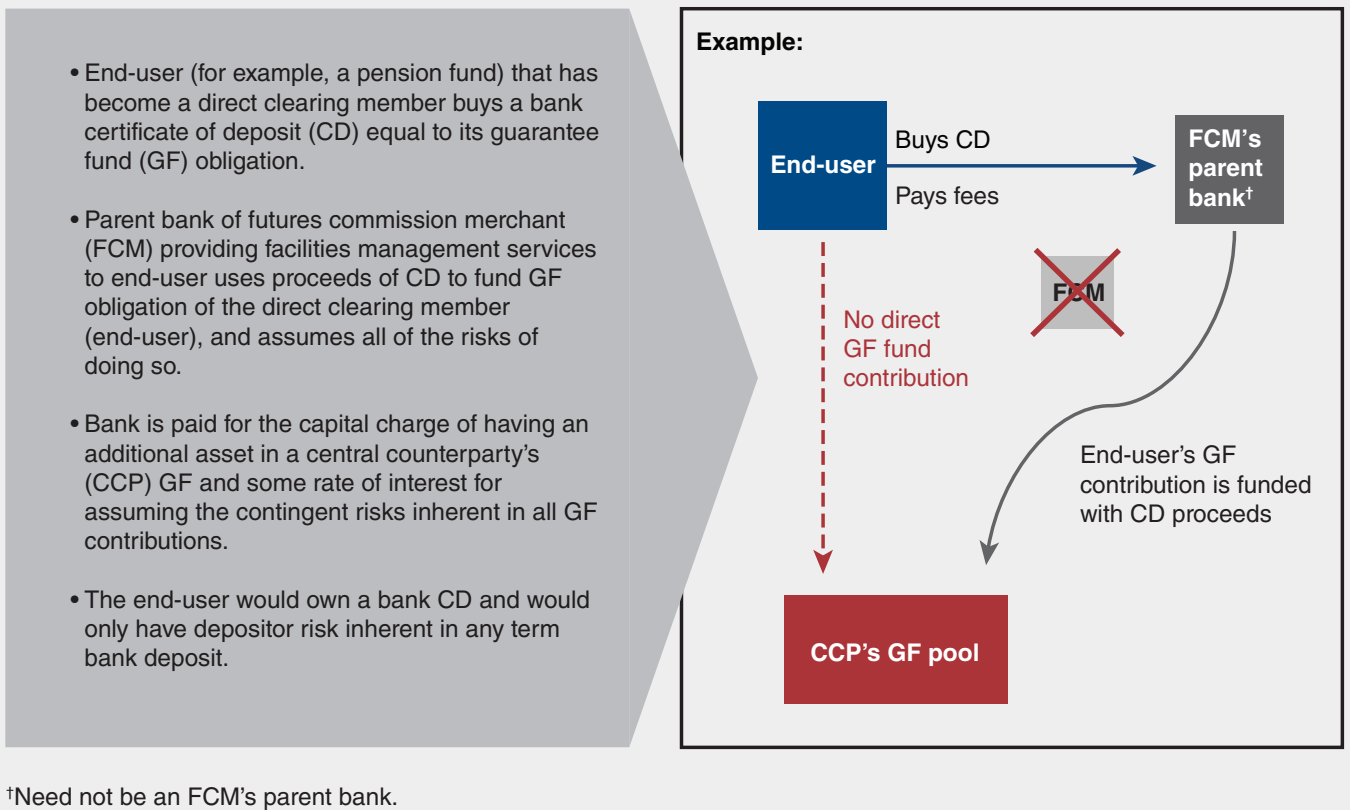

Potential direct clearing members would still face the contingent exposure of being assessed by the CCP if a default loss were to exceed all of the prefunded financial resources of the CCP. While this is uncommon, potential direct clearing members might protect themselves against the remote risk of being assessed by the CCP by purchasing some insurance or indemnification policy from a third-party surety. ${ }^{25}$

\section{Challenge 3: The requirement to participate in afternoon or ad hoc settlement cycles that might require} substantial amounts of same-day funds

While IM and VM help mitigate market and credit risk in central clearing, they also create liquidity risk in the system in a number of ways. When a CCP issues a margin call, it requests payments from its clearing members; in turn, these members request payments from the customers they are clearing for. The clearing members' customers then instruct their banks to make payments on their behalf to their clearing members' settlement banks. In an ideal world, these payments would happen within seconds of each other and sequentially. In reality, there is usually an overnight lag between the CCP collecting from the clearing member and the clearing member collecting from its customers, as the customers need confirmation of their transactions and positions, which they receive overnight from their clearing member. ${ }^{26}$ Therefore, clearing members fund daily and intraday obligations on behalf of their customers on the same day, and typically settle with their customers the morning of the next business day.

Importantly, clearing members are subject to tight settlement time frames (as narrow as one hour) to meet margin calls, including intraday margin calls. Under the present CCP settlement framework, cash is the only financial asset that can satisfy both an IM obligation and a VM obligation to a CCP. ${ }^{27}$ Therefore, clearing members must have substantial amounts of cash readily available. Missing a margin call is deemed to be an event of default. So, clearing members are left with no choice but to hold substantial excess liquid financial resources at all times. 


\section{FIGURE 6}

\section{Adjusted central counterparty (CCP) settlement processes for variation margin (VM)}

A. When a clearing member has a net VM gain
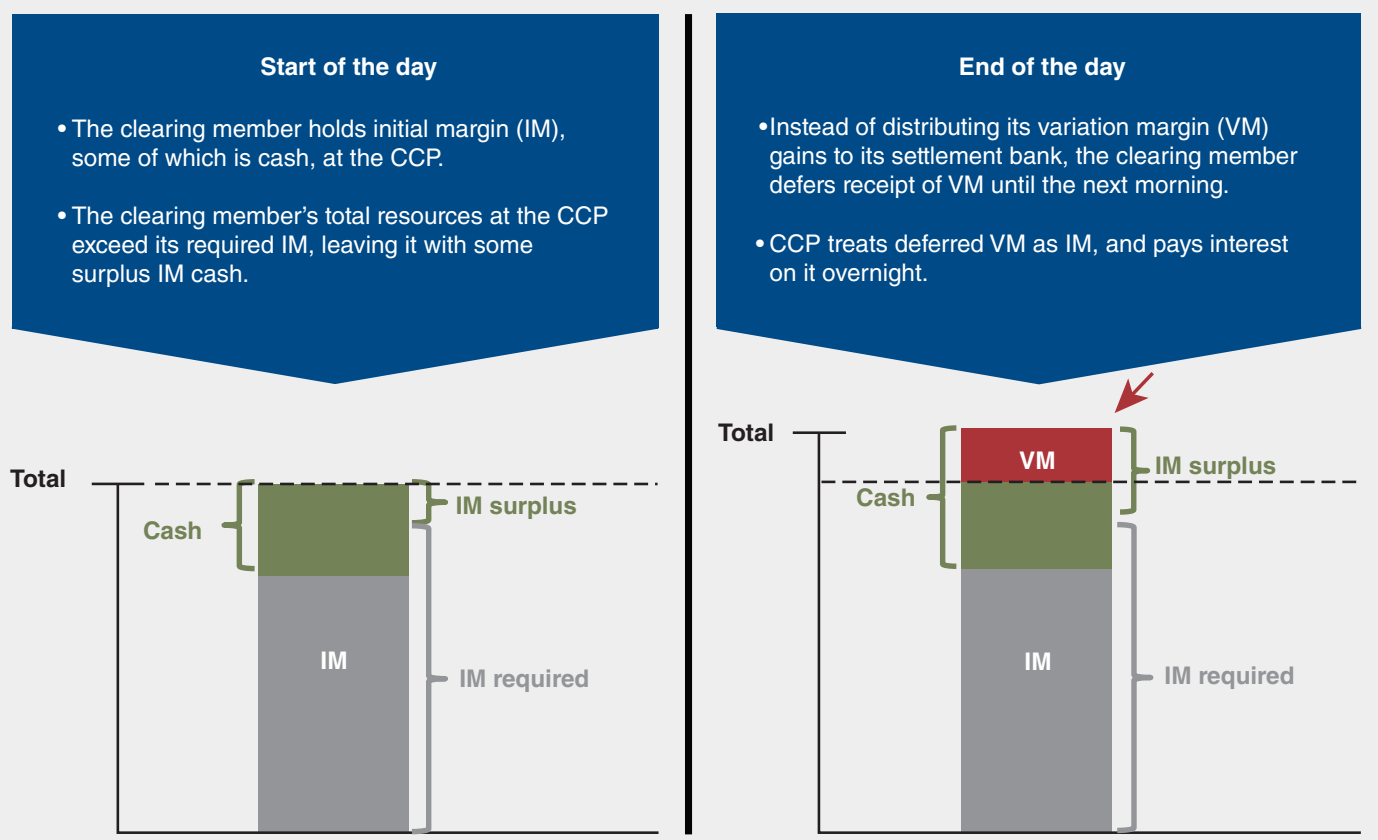

\section{B. When a clearing member has a net VM loss}
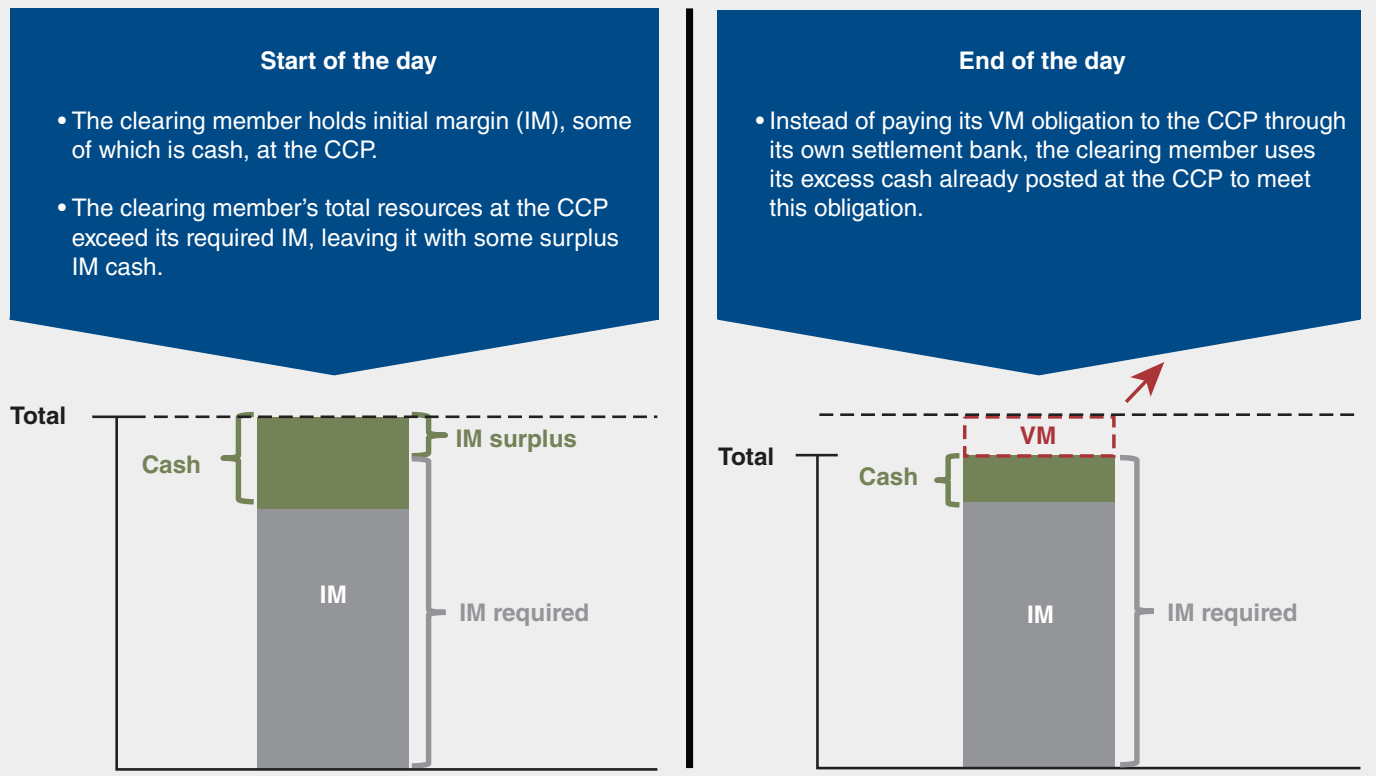

Note: See the text for further details. 
In order for the concept of direct clearing by end-users to work in practice, CCPs would likely need to adjust their settlement processes. These adjustments would allow end-users that have become direct clearing members to participate in afternoon or ad hoc settlement cycles without holding substantial amounts of same-day funds. These settlement options would be made available to all clearing members. Indeed, CME Clearing, LCH.Clearnet (LCH), and Eurex Clearing already offer some of the following settlement options to their clearing members. For end-users that become direct clearing members, the adjustments are fairly straightforward. For existing clearing members with clients, however, there are a few additional considerations that I go on to describe.

- For clearing members that have net VM gains, CCPs could offer the option of deferring receipt of VM cash until the following morning. The proposed change would allow the clearing members' VM cash to remain at the $\mathrm{CCP}$ overnight rather than with the clearing members' settlement banks. The CCP would treat this VM cash as excess IM cash, paying clearing members interest on it until the clearing member needs to withdraw it to pay its customers, most likely the following morning (when clearing members with clients would need to pass on the gains to their clients), as shown in panel A of figure 6. CME Clearing has already implemented this option.

- Then, to clearing members that have net VM losses (that is, clearing members that owe the CCP VM), CCPs could allow them to (partially or totally) cover their VM obligations with excess IM cash in their account at the CCP. This would reduce or eliminate the VM calls that the CCP would otherwise issue to the clearing members and the clearing members' banks, as shown in panel B of figure $6{ }^{28}$ Several CCPs have implemented this option.

- Clearing members obligated to pay VM in the afternoon that do not have enough excess IM cash in their accounts could temporarily satisfy (partially or totally) their VM obligation to the CCP with excess IM sovereign debt securities until the following morning. Through a repurchase agreement (see figure 7 and note 14), the CCP could then pay VM cash to other clearing members that elected not to defer receipt of VM cash that afternoon. Once the clearing member remits the VM cash in the correct currency to the $\mathrm{CCP}$ by the end of the next settlement cycle, the $\mathrm{CCP}$ would return the sovereign debt securities.

\section{FIGURE 7}

\section{Central counterparties (CCPs) allowing clearing members to collateralize} variation margin (VM) obligations with sovereign debt securities

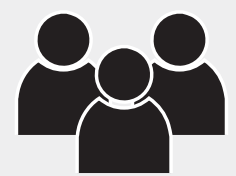

1.

Instead of paying its VM obligation to the CCP through its settlement bank, the clearing member collateralizes its VM obligation with sovereign debt securities it has posted at the CCP.

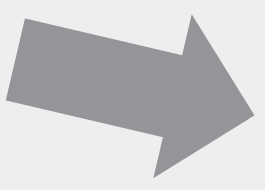

\section{2.}

The CCP obtains the cash it needs to pay VM to other clearing members through a repurchase agreement (repo) transaction (selling the sovereign debt securities and buying them back the next morning).

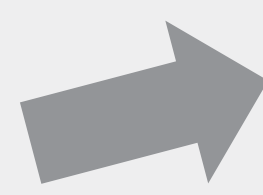

3.

- The CCP needs a repo facility that can find a party to buy the securities and then sell them back.

- Or the CСP can internalize the repo transaction if it has enough cash. 
Today Eurex Clearing allows clearing members to satisfy a VM obligation overnight with sovereign debt securities subject to haircuts. ${ }^{29}$ The VM is then due in the proper currency the following morning. LCH allows its clearing members to do something fairly similar. LCH conducts multiple settlement cycles during the course of the trading day. Its last settlement cycle occurs in the afternoon at a time when the only major payment system that is open is Fedwire. LCH collects U.S. dollars as overnight cover for VM obligations in multiple currencies. When clearing members post VM the following morning in the proper currency, LCH returns their U.S. dollar cover. Collecting a credit-risk-free asset as overnight cover for a VM obligation is not a new concept.

However, by adjusting the settlement process in the aforementioned way, the CCP faces new challenges. One of these challenges is what to do if most of the clearing member accounts that have an obligation to pay VM are clearing member customer accounts and most clearing member accounts that are collecting VM from the CCP are house accounts. In this scenario, most of the collective VM obligations of the customer accounts could not be collateralized with sovereign debt securities because the vast majority of the VM cash would be going to house accounts in the afternoon.

Having a highly reliable source to finance sovereign debt securities overnight would eliminate the binding constraint that arises when few clearing members are willing to defer receipt of VM cash (for their house accounts) and too many clearing members want to temporarily satisfy their VM obligation with sovereign debt securities (for their customer accounts). There is anecdotal evidence to suggest that clearing members are less likely to defer collecting VM cash for their house accounts in the afternoon, so the VM deferral concept would likely be more relevant for use with clearing members' customer accounts.

Absent a highly reliable repo facility, the aggregate amount of VM that clearing members could temporarily satisfy with sovereign debt securities would otherwise be limited to the aggregate amount of VM that was deferred by clearing members during that settlement cycle. ${ }^{30}$ Therefore, CCPs need access to robust repo facilities.

CCPs could internalize the repo transaction (instead of engaging with an outside repo counterparty) if they have a substantial and highly reliable source of cash. There is a realistic possibility that CCPs would have attracted a substantial amount of cash from clearing members, if the CCPs were paying a market rate of interest on IM cash. ${ }^{31}$ Should a CCP permit sovereign debt securities to be temporarily substituted for cash, that CCP could internalize the repo transaction against the sizable pool of IM cash that it already holds. This would be a particularly effective strategy if the stable amount of IM cash held by the CCP were well in excess of the largest historical VM settlements of the CCP.

Clearing members electing to temporarily substitute sovereign debt securities for VM would also be obligated to pay the $\mathrm{CCP}$ (and indirectly the collecting clearing members) the going rate of interest on the amount of deferred VM that the CCP and the collecting clearing members would otherwise have earned overnight. In this way, the CCP would then be in a position to pay some portion of that interest to the clearing members electing to defer receipt of VM.

Clearing members electing to collateralize their VM obligations with sovereign debt securities would then need to make an informed estimate of what the overnight repo financing rate would be from day to day. They would also have to pay the CCP the higher of 1) the rate of interest that the CCP would earn on overnight IM cash or 2) the overnight repo rate on the sovereign debt securities that would need to be financed.

Alternatively, since many potential direct clearing members are insurance companies, pension funds, and sovereign wealth funds, their settlement banks could easily finance the afternoon VM obligations of such 
enterprises if they were secured by relevant securities portfolios held in custody by the settlement banks. A direct clearing member that had made such a financing arrangement would not have to collateralize its VM obligations at the CCP because the settlement bank would make payments (which are secured by that clearing member's securities portfolio) to the CCP. Ideally, the direct clearing member would deposit a generous amount of securities that it knew it was likely to hold to maturity with the settlement bank, providing ample collateral for the settlement bank to always make settlement on behalf of that clearing member. The beneficial ownership of the securities would be unaffected; and if the securities deposited with the settlement bank were securities that were likely to be held to maturity, collateral substitutions would be nil. Those securities would only be encumbered overnight and only when the settlement bank provided VM to the $\mathrm{CCP}$ because the direct clearing member otherwise had insufficient funds in its account.

Despite these possible solutions to the aforementioned challenges, it is uncertain whether end-users would perceive the advantages of direct clearing membership as greater than the responsibilities and operational inconvenience of settling on a very rigid settlement cycle (as all clearing members must do) with the CCP.

\section{Conclusion}

Even if the practical obstacles to direct clearing by end-users can be overcome, concerns over admitting new members to the loss mutualization club formed by a CCP remain. For example, some have argued that such new direct clearing members may pose greater risk to CCPs given that they would not have an established clearing member to guarantee their financial performance to the CCP (FIA, 2018, p. 5). However, bank-affiliated FCMs already take large positions in their house accounts, which are not subject to any credit intermediation and carry risk of their own. Furthermore, end-users that become direct clearing members could still be subject to stringent membership criteria to ensure that they did not pose undue risks. In addition, the risks posed by new direct clearing members need to be balanced against the risk-mitigation benefits of enlarging and diversifying the group of firms that participate in a CCP.

CCPs offer significant benefits to financial markets, but these benefits do not come without potential risks. Of particular concern is the concentration of outstanding cleared derivatives (and associated financial resources) among large clearing members at CCPs. In this article, I explained some of the possible adverse consequences of this concentration that others have raised. Then I explored one potential solution to the issue - to allow the largest and most creditworthy end-users to become direct clearing members of CCPs in order to increase and diversify CCP clearing membership. I also discussed some of the challenges that have thus far inhibited end-users from becoming direct clearing members. Finally, I discussed some of the ways these challenges might be overcome. In doing so, I looked at the current settlement practices of certain international CCPs that are bringing on some large end-users as direct clearing members.

My hope is that this article has contributed meaningfully to the ongoing public policy discussions concerning the growing concentration of derivatives clearing - and the ways in which this challenge might be addressed.

\footnotetext{
Notes

${ }^{1}$ For further details, see the action plan set forth in Group of Twenty (2008).

${ }^{2}$ For more-technical definitions of the terms house account (or house origin) and customer account (or customer origin) from the U.S. Commodity Futures Trading Commission (CFTC), see 17 CFR § 39.2, available online, https://www.ecfr.gov/cgi-bin/ text-idx?SID=aa28462eee43381d7a7737951c76d70b\&mc=true\&node=pt17.1.39\&rgn=div5\#se17.1.39_12.
} 
${ }^{3}$ Some common types of derivatives contracts are futures (by which two counterparties agree to buy or sell a specified amount of an asset at a prearranged price at or by a set date), options (by which the holder has the right, but not the obligation, to buy or sell the underlying asset at a prearranged price at or by a set date), swaps (by which two counterparties agree to exchange one stream of income for another, such as variable-interest payments for fixed-interest payments), and hybrids (for example, an option on a future).

${ }^{4}$ Norman (2011) explained that "within a week of the Lehman bankruptcy, most outstanding open positions relating to these trades had been neutralised or 'hedged' so that they no longer threatened further losses to creditors or to add more chaos to the world financial system" and that "within two weeks, most of Lehman's customer accounts were transferred to other investment companies."

${ }^{5}$ The way in which a client's relationship with its clearing member is structured varies across jurisdictions. For instance, in Europe, under the European Market Infrastructure Regulation (EMIR) and related laws, clearing members provide indirect clearing services on a principal-to-principal basis, meaning that trade intermediation involves back-to-back transactions between: 1) the clearing member and the CCP and 2) the clearing member and its client. In the United States, clearing members deal with the CCP as agents for their clients (Braithwaite, 2016).

${ }^{6}$ Under the Commodity Exchange Act, a futures commission merchant is an individual, association, partnership, corporation, or trust that: 1) solicits or accepts orders for relevant transactions and 2) holds money, securities, or property (or provides credit in lieu thereof) in order to margin, guarantee, or secure trades or contracts. For further details, see 7 USC $\S 1 \mathrm{a}(28)$, available online, https://www.law.cornell.edu/uscode/text/7/1a\#28.

${ }^{7}$ Though outside of the scope of this article, another closely related issue is the concentration of prefunded financial resources (that is, initial margin plus the guarantee fund) at a small number of CCPs. According to estimates for 2017, the two largest CCPs (as measured by prefunded financial resources) accounted for almost 40 percent of total prefunded financial resources at all CCPs (up from 32 percent in 2016); the next largest eight CCPs accounted for 50 percent of such resources (Basel Committee on Banking Supervision et al., 2018b, p. 4).

${ }^{8}$ Total customer funds (that is, only client margin in the U.S. context) are required customer assets in segregation from the FCM's own; required funds in separate section 30.7 accounts (for foreign futures or foreign options secured amounts); and required funds in separate cleared swap segregation accounts.

${ }^{9}$ One reason for the possible overstatement is that in the United States, the SLR uses the notional principal of both proprietary and customer derivatives contracts on the bank's books in the calculation of assets. This means the SLR treats the entire notional size of a derivatives contract as if it represented the total potential loss given default and hence does not account for the fact that losses on some contracts in the portfolio would be offset by corresponding gains in contracts on the other side of the trade. Another reasons is, as originally implemented, the SLR made no allowance for the risk-exposure-reducing impact of initial margin (Giancarlo, 2017).

${ }^{10}$ Any capital charge such as the SLR is a marginal cost that a bank incurs when it puts an asset on its balance sheet and, as such, reduces the incentive to acquire that asset. The benefit of the higher capital is the reduced odds of bank default and economic externalities associated with that default.

${ }^{11}$ The standard-setting bodies are the Basel Committee on Banking Supervision (BCBS); the Committee on Payments and Market Infrastructures (CPMI); the Financial Stability Board (FSB); and the International Organization of Securities Commissions (IOSCO).

12 “Juniorized" means prioritized in absorbing potential default losses. For more information, see Lewis and McPartland (2018).

${ }^{13}$ Further details on Eurex Clearing's ISA Direct are available online, http://www.eurexclearing.com/clearing-en/marketsservices/isa-direct.

${ }^{14}$ Repurchase agreements are typically short-term (usually overnight) financial transactions that involve the sale of a security and the subsequent repurchase of the same security. Repos enable market participants selling securities to obtain immediate funds and market participants buying securities to earn short-term interest on their funds. As such, the securities function as collateral for short-term loans.

${ }^{15} \mathrm{CME}$ Clearing withdrew its DFP proposal from the CFTC in late 2018. 
${ }^{16}$ Further details on the FICC's Sponsored Membership are available online, http://www.dtcc.com/clearing-services/ficc-gov/ sponsored-membership.

${ }^{17}$ If a direct clearing member were guaranteed by another clearing member and the guaranteeing clearing member were to default, the direct clearing member would need to either obtain the services of another guaranteeing clearing member or revert to being a customer of a clearing member.

${ }^{18}$ The IM cash of customers that became direct clearing members would also no longer be included in the parent bank's calculation of its liquidity coverage ratio and its net stable funding ratio; for details on these ratios, see Bank for International Settlements, Financial Stability Institute (2018a, 2018b).

${ }^{19}$ Under CFTC regulations, an FCM is required to compute the aggregate amount of its futures customers' undermargined accounts as of the close of business each day. The FCM must then maintain a sufficient amount of its own funds (residual interest) in its customer segregated accounts by the residual interest deadline of 6:00 p.m. Eastern Time on the next business day to cover the customer's undermargined amounts that were computed as of the close of business the previous day. See 17 CFR § 1.22(c)(5), available online, https://www.law.cornell.edu/cfr/text/17/1.22.

${ }^{20} \mathrm{~A}$ beneficial owner is an entity that enjoys the benefits of owning the portfolio (or individual derivative, security, or property) but does not legally own it.

${ }^{21}$ Systemically important CCPs in the U.S. are eligible to request interest-bearing deposit accounts at their relevant Federal Reserve Banks, according to the Fed's Regulation HH (details are available online, https://www.federalreserve.gov/paymentsystems/ reghh-about.htm). These accounts allow CCPs to avoid some of the depository risk associated with holding the balances of clearing members at commercial banks; these accounts also provide CCPs a flexible way to manage clearing member balances on days when margin payments unexpectedly rise or fall. For more information on central bank accounts for CCPs, see Steigerwald (2017).

${ }^{22}$ Pension funds are likely to be precluded from distributing pension fund assets to those other than pensioners. Similarly, life insurance companies are likely to be precluded from exposing life insurance portfolio assets to factors other than mortality risks.

${ }^{23}$ In theory, this function could be provided by any creditworthy surety. The surety would have the guarantee fund contribution self-funded by the direct clearing member and simply assume the financial risk of a default that would require drawing from the mutualized guarantee fund. Any number of companies could provide this service. It is important that the FCM is not a party to this transaction. If it were, it could be mischaracterized that the FCM was in some way guaranteeing the financial performance of the direct clearing member to the CCP.

${ }^{24}$ The certificate of deposit could also be sold in the CD secondary market, leaving the pension fund with no exposure at all.

${ }^{25} \mathrm{~A}$ distinction needs to be made between an assessment and a replenishment of a contribution to a guarantee fund. Clearing members have occasionally been required to partially replenish their respective contributions to a CCP's guarantee fund. But clearing members are required even less frequently to pay assessments to make up for default losses that exceed the mutualized guarantee fund, given that such events are exceedingly rare.

${ }^{26}$ Regulations require that customer positions be valued at official settlement prices that are typically only available at the end of the trading day.

${ }^{27}$ There are some exceptions to this, but usage of those asset classes is limited enough to not be material to this discussion.

${ }^{28}$ For the bank of a clearing member with clients, using excess segregated IM cash at the CCP to partially or totally satisfy a VM obligation (of the customer account) will diminish the VM obligation that would otherwise be demanded at the settlement bank, dollar for dollar. This will temporarily diminish the cash component of the clearing member's segregated assets at the CCP, but the clearing member's overall segregated cash depletion would be no greater than if the entire VM obligation were charged against the clearing member's customer segregated funds account at its settlement bank.

${ }^{29} \mathrm{~A}$ haircut is the difference between the market value of a security (or other asset) and its lower value when being used as collateral. Sovereign debt securities are often used as collateral for overnight borrowing arrangements or repurchase agreements. The amount of the haircut is a function of the amount of associated risk. 
${ }^{30}$ This could be an ideal application for distributed ledger technology. It involves the title transfer of assets (in this case, sovereign debt securities) under tight time frames, a trusted agent (the CCP), and visibility into the blockchain by affected clearing members (beneficiaries). Legal certainty could be achieved by codifying the blockchain in the CCP's rulebook, which would presumably be respected and enforced by a court of competent jurisdiction. It is assumed that the CCP would first establish a security interest in sovereign debt securities with the smallest haircut. The system for doing so would need to be programmed to determine the smallest denomination of each CUSIP (Committee on Uniform Securities Identification Procedures) number (the nine-digit alphanumeric code used to identify securities in the U.S. and Canada). Title transfers of the sovereign debt securities would be made while recognizing the proper minimum denominations and making the proper haircuts. Title to the sovereign debt securities would be transferred back to the proper clearing member/accounts on the blockchain after VM was collected in full during the next settlement cycle. Having the relevant custodians as nodes on the blockchain could enable this process to occur promptly and at minimum cost.

${ }^{31}$ This has been facilitated to some degree in the United States by systemically important CCPs having interest-bearing deposit accounts directly with Federal Reserve Banks (see note 21).

\section{References}

Acosta-Smith, Jonathan, Gerardo Ferrara, and Francesc Rodriguez-Tous, 2018, "The impact of the leverage ratio on client clearing," Bank of England, staff working paper, No. 735, June 15, available online, https://www.bankofengland.co.uk/working-paper/2018/the-impact-of-the-leverage-ratio-on-client-clearing.

Bank for International Settlements, Financial Stability Institute, 2018a, "Net stable funding ratio (NSFR) Executive summary,” FSI Connect, Basel, Switzerland, June 28, available online, https://www.bis.org/fsi/ fsisummaries/nsfr.htm.

Bank for International Settlements, Financial Stability Institute, 2018b, "Liquidity coverage ratio (LCR) Executive summary," FSI Connect, Basel, Switzerland, April 30, available online, https://www.bis.org/fsi/ fsisummaries/lcr.htm.

Barnes, Chris, 2017, “Clearing mandates 2017,” Clarus Financial Technology, blog, June 7, available online, https://www.clarusft.com/clearing-mandates-2017/.

Basel Committee on Banking Supervision, 2019, "Leverage ratio treatment of client cleared derivatives," report, Basel, Switzerland, June, available online, https://www.bis.org/bcbs/publ/d467.pdf.

Basel Committee on Banking Supervision, Committee on Payments and Market Infrastructures, Financial Stability Board, and International Organization of Securities Commissions, 2018a, Incentives to Centrally Clear Over-the-Counter (OTC) Derivatives: A Post-Implementation Evaluation of the Effects of the G20 Financial Regulatory Reforms-Final Report, Basel, Switzerland, November 19, available online, https://www.bis.org/publ/othp29.htm.

Basel Committee on Banking Supervision, Committee on Payments and Market Infrastructures, Financial Stability Board, and International Organization of Securities Commissions, 2018b, "Analysis of central clearing interdependencies," report, Basel, Switzerland, August 9, available online, https://www.bis.org/cpmi/publ/d181.htm.

Basel Committee on Banking Supervision, Committee on Payments and Market Infrastructures, Financial Stability Board, and International Organization of Securities Commissions, 2017, "Analysis of central clearing interdependencies," report, Basel, Switzerland, July 5, available online, http://www.fsb.org/2017/07/analysis-of-central-clearing-interdependencies/.

Behnam, Rostin, 2018, "A decade after the financial crisis: Remaining challenges and new approaches for the next ten years and beyond," keynote remarks of U.S. Commodity Futures Trading Commission (CFTC) commissioner at the Federal Reserve Bank of Chicago's fifth annual Conference on CCP Risk Management, Chicago, October 16, available online, https://www.cftc.gov/PressRoom/SpeechesTestimony/opabehnam10. 
Berkovitz, Dan M., 2019, "Take it to the limit, one more time (again)," keynote address of U.S. Commodity Futures Trading Commission (CFTC) commissioner at the FIA Commodities Symposium, Houston, June 11, available online, https://www.cftc.gov/PressRoom/SpeechesTestimony/opaberkovitz4.

Braithwaite, Jo, 2016, "The dilemma of client clearing in the OTC derivatives markets," European Business Organization Law Review, Vol. 17, No. 3, September, pp. 355-378. Crossref, https://doi.org/10.1007/ s40804-016-0044-0

Cox, Robert T., and Robert S. Steigerwald, 2018, "A CCP is a CCP is a CCP," Journal of Financial Market Infrastructures, Vol. 6, No. 4, June, pp. 1-18. Crossref, https://doi.org/10.21314/JFMI.2018.085

European Securities and Markets Authority, 2016, "Final report on the clearing obligation for financial counterparties with a limited volume of activity," Paris, November 14, available online, https://www.esma. europa.eu/sites/default/files/library/2016-1565_final_report_on_clearing_obligation.pdf.

Evanoff, Douglas D., Daniela Russo, and Robert S. Steigerwald, 2006, "Policymakers, researchers, and practitioners discuss the role of central counterparties," Economic Perspectives, Federal Reserve Bank of Chicago, Vol. 30, Fourth Quarter, pp. 2-21, available online, https://www.chicagofed.org/ publications/economic-perspectives/2006/4qtr2006-part1-evanoff-etal.

FIA, 2018, "Central clearing: Recommendations for CCP risk management," report, Washington, DC, November, available online, https://fia.org/file/8326/download?token=arZLqCOp.

FIA, 2012, "Protection of customer funds: Frequently asked questions - Version 2.0," report, Washington, DC, June, available online, https://secure.fia.org/downloads/PCF-FAQs.pdf.

Financial Crisis Inquiry Commission, 2011, The Financial Crisis Inquiry Report: Final Report of the National Commission on the Causes of the Financial and Economic Crisis in the United States, official government ed., Washington, DC: U.S. Government Printing Office, available online, https://www.govinfo.gov/ app/details/GPO-FCIC/summary.

Giancarlo, J. Christopher, 2017, "Changing swaps trading liquidity, market fragmentation and regulatory comity in post-reform global swaps markets," remarks of the U.S. Commodity Futures Trading Commission (CFTC) acting chairman before the International Swaps and Derivatives Association's 32nd Annual General Meeting, Lisbon, Portugal, May 10, available online, https://www.cftc.gov/PressRoom/ SpeechesTestimony/opagiancarlo-22.

Group of Twenty, 2008, Declaration of the Summit on Financial Markets and the World Economy, Washington, DC, November 15, available online, https://georgewbush-whitehouse.archives.gov/news/ releases/2008/11/20081115-1.html.

Haynes, Richard, Lihong McPhail, and Haoxiang Zhu, 2018, "Assessing the impact of the Basel III leverage ratio on the competitive landscape of US derivatives markets: Evidence from options," U.S. Commodity Futures Trading Commission, policy brief, June 15, available online, https://www.cftc.gov/ sites/default/files/About/Economic\%20Analysis/oce_leverage_and_options.pdf.

Heckinger, Richard, 2013, "Derivatives overview," in Understanding Derivatives: Markets and Infrastructure, Chicago: Federal Reserve Bank of Chicago, Financial Markets Group, pp. 1-11, available online, https://www.chicagofed.org/publications/understanding-derivatives/index.

ICE Clear Europe, 2019, “Customer protection framework-Version 1.2," report, London, July, available online, https://www.theice.com/publicdocs/clear_europe/Customer_Protection_Framework.pdf. 
International Swaps and Derivatives Association, 2019, “CCP best practices," report, New York, January, available online, http://assets.isda.org/media/b53b5127/55872319-pdf/.

Lazarow, Alexandre, 2011, "Lessons from international central counterparties: Benchmarking and analysis," Bank of Canada, discussion paper, No. 2011-4, June, available online, https:/www.bankofcanada.ca/wp-content/ uploads/2011/06/dp2011-04.pdf.

Lewis, Rebecca, and John McPartland, 2018, "One for my baby (and one more for the road): Incentives, default waterfalls and central counterparty skin-in-the-game, ” Journal of Financial Market Infrastructures, Vol. 6, No. 4, June, pp. 55-70. Crossref, https://doi.org/10.21314/JFMI.2018.096

Madigan, Peter, 2015, "Goldman hikes clearing fees by 75bp as leverage ratio bites," Risk.net, March 24, available online by subscription, https://www.risk.net/derivatives/2401060/

goldman-hikes-clearing-fees-75bp-leverage-ratio-bites.

McPartland, John, 2005, "Clearing and settlement demystified," Chicago Fed Letter, Federal Reserve Bank of Chicago, No. 210, January, available online, https://www.chicagofed.org/publications/chicagofed-letter/2005/january-210.

Moser, James T., 1994, "Origins of the modern exchange clearinghouse: A history of early clearing and settlement methods at futures exchanges," Federal Reserve Bank of Chicago, working paper, No. 94-3, April, available online, https://fraser.stlouisfed.org/files/docs/historical/frbchi/workingpapers/frbchi workingpaper_1994-03.pdf.

Norman, Peter, 2011, The Risk Controllers: Central Counterparty Clearing in Globalised Financial Markets, Chichester, UK: John Wiley and Sons.

Novick, Barbara, Hubert De Jesus, Stephen Fisher, Eileen Kiely, Mariam Osman, and Vicky Hsu, 2018, "An end-investor perspective on central clearing: Looking back to look forward," ViewPoint, BlackRock, September, available online, https:/www.blackrock.com/corporate/literature/whitepaper/ viewpoint-end-investor-perspective-central-clearing-looking-back-to-look-forward.pdf.

Parsons, Joe, 2018, "FIS signs third client to derivatives post-trade utility, targets further evolution," TRADE, January 9, available online, https://www.thetradenews.com/

fis-signs-third-client-to-derivatives-post-trade-utility-targets-further-evolution/.

Parsons, Joe, 2017, "European banks downsizing role in client clearing," TRADE, January 13, available online, https://www.thetradenews.com/european-banks-downsizing-role-in-client-clearing/.

Peirce, Hester, 2017, "Dwindling numbers in the financial industry," Series on Financial Markets and Regulation, Brookings Institution, Center on Regulation and Markets, May 15, available online, https://www.brookings.edu/research/dwindling-numbers-in-the-financial-industry/.

Powell, Jerome H., 2017, "Central clearing and liquidity," speech by Federal Reserve Governor at the Federal Reserve Bank of Chicago Symposium on Central Clearing, Chicago, June 23, available online, https://www.federalreserve.gov/newsevents/speech/powell20170623a.htm.

Quintenz, Brian, 2018, opening statement of U.S. Commodity Futures Trading Commission (CFTC) commissioner before the CFTC Market Risk Advisory Committee, Washington, DC, December 4, available online, https://www.cftc.gov/PressRoom/SpeechesTestimony/quintenzstatement120418. 
Rundle, James, 2017, "Clearing portability under threat as FCM pool shrinks," Risk.net, February 23, available online by subscription, https://www.risk.net/risk-management/3912341/

clearing-portability-under-threat-as-fcm-pool-shrinks.

Siedlecki, Sven, 2017, "Concentration risks in financial market infrastructures-The specific case of CCPs," in Financial Market Infrastructures and Payment Services, National Bank of Belgium, report, June, pp. 91-94, available online, https://www.nbb.be/doc/ts/publications/fmi-and-paymentservices/2017/2017-3concentration-risks-in-ccps.pdf.

Steigerwald, Robert S., 2017, statement by senior policy advisor, Financial Markets Group, Federal Reserve Bank of Chicago (as part of the "Clearing the next crisis: Resilience, recovery, and resolution of derivative clearinghouses" hearing), before the U.S. House of Representatives, Committee on Agriculture, Washington, DC, June 27, available online, https://www.gpo.gov/fdsys/pkg/CHRG-115hhrg26115/html/CHRG-115hhrg26115.htm.

U.S. Commodity Futures Trading Commission, Market Risk Advisory Committee, 2015, meeting transcript, Washington, DC, June 2, available online, https://www.cftc.gov/sites/default/files/idc/groups/ public/@aboutcftc/documents/file/mrac_060215_transcript.pdf.

Vaghela, Viren, 2015, "Nomura exec: Client clearing scale insufficient outside Japan,” Risk.net, June 19, available online by subscription, https://www.risk.net/derivatives/2413761/

nomura-exec-client-clearing-scale-insufficient-outside-japan.

Vuillemey, Guillaume, 2019, "The value of central clearing," HEC Paris, research paper, No. FIN-2018-1307, August 5. Crossref, https://doi.org/10.2139/ssrn.3247551

Nahiomy Alvarez is a senior analyst in the Financial Markets Group at the Federal Reserve Bank of Chicago. The author would like to thank the many industry professionals who contributed feedback on earlier versions of this article; Spencer Krane, Sam Schulhofer-Wohl, Robert Steigerwald, and the late Robert Cox for helpful comments and discussions; and John McPartland for his guidance and major contribution to this work.

C 2019 Federal Reserve Bank of Chicago

Economic Perspectives is published by the Economic Research Department of the Federal Reserve Bank of Chicago. The views expressed are the authors' and do not necessarily reflect the views of the Federal Reserve Bank of Chicago or the Federal Reserve System.

Charles L. Evans, President; Anna L. Paulson, Executive Vice President and Director of Research; Daniel G. Sullivan, Executive Vice President, outreach programs; Spencer Krane, Senior Vice President and Senior Research Advisor; Sam Schulhofer-Wohl, Senior Vice President, financial policy; Daniel Aaronson, Vice President, microeconomic policy research; Gene Amromin, Vice President, finance team; Alessandro Cocco, Vice President, markets team; Jonas D. M. Fisher, Vice President, macroeconomic policy research; Leslie McGranahan, Vice President, regional research; Marcelo Veracierto, Senior Economist and Economics Editor; Helen Koshy and Han Y. Choi, Editors; Julia Baker, Production Editor; Sheila A. Mangler, Editorial Assistant.

Economic Perspectives articles may be reproduced in whole or in part, provided the articles are not reproduced or distributed for commercial gain and provided the source is appropriately credited. Prior written permission must be obtained for any other reproduction, distribution, republication, or creation of derivative works of Economic Perspectives articles. To request permission, please contact Helen Koshy, senior editor, at 312-322-5830 or email Helen.Koshy@chi.frb.org.

ISSN 0164-0682 